\title{
CT Features of Early Pheochromocytoma
}

Takashi Sugawara, Tomoko Hashimoto, Masahiko Owada and Minoru Kawamura

Key words: pheochromocytoma, adrenal incidentaloma, CT

(Intern Med 50: 787, 2011)

(DOI: 10.2169/internalmedicine.50.4531)

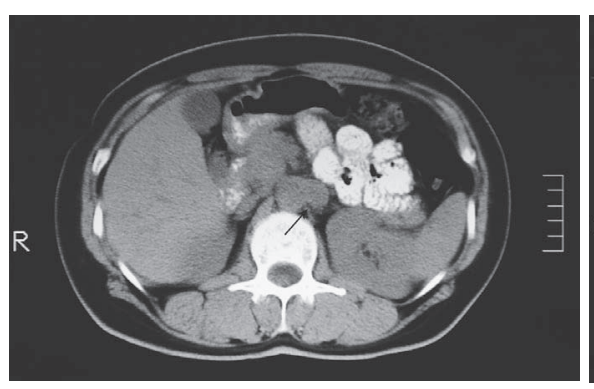

Picture 1.

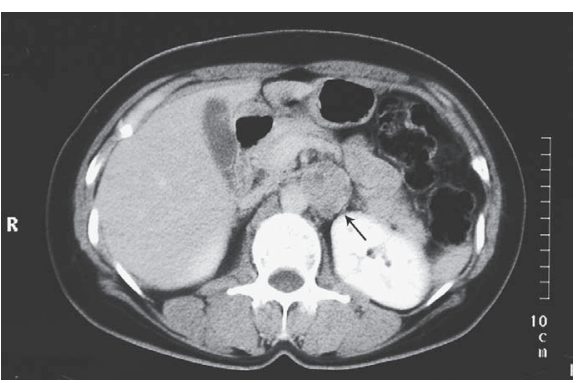

Picture 2.

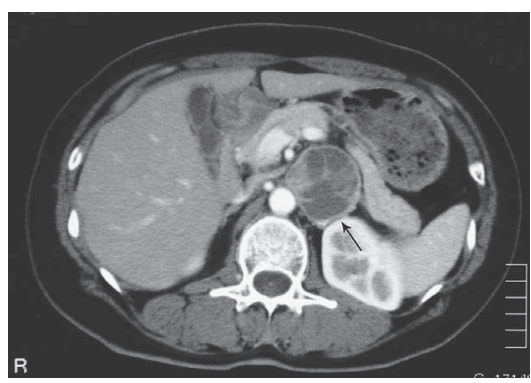

Picture 3.
A 53-year-old woman was found to have a left-sided peritoneal mass by CT during follow-up of a gallbladder polyp at the Gastrointestinal Department of our hospital. Unenhanced CT showed a round mass that was $2.0 \mathrm{~cm}$ in diameter with a well-defined margin. The lesion was homogenous with a comparatively high CT value (30 HU) (Picture 1). On enhanced CT, the mass showed homogenous enhancement $(85 \mathrm{HU}$ in the early phase and $75 \mathrm{HU}$ in the late phase). At first, an enlarged lymph node was suspected without confirming continuity with the adrenal gland. Twenty-six months later, enhanced CT showed enlargement of the mass to $3.3 \mathrm{~cm}$ in diameter and development of cystic areas (Picture 2). Thirty-nine months after detection of the mass, enhanced CT showed further enlargement to $4.1 \mathrm{~cm}$ in diameter with heterogenous cystic areas (indicating necrosis or bleeding) (Picture 3), which were the typical characteristics of a pheochromocytoma (1). The patient was then referred to our department for further examination. Spot urinary total metanephrine was $1.51 \mathrm{mg} / \mathrm{gram}$ creatinine, which was above normal (0.6 mg/gram creatinine) $(2)$, and ${ }^{123} \mathrm{I}-$ metaiodobenzylguanidine scanning was positive for pheo- chromocytoma. The mass was resected and was confirmed to be a left adrenal pheochromocytoma by pathological examination. This is the first report on the CT imaging characteristics of early pheochromocytoma. Based on our experience, early pheochromocytoma can be indistinguishable from an adrenal incidentaloma by CT. The mass was calculated to have increased in diameter by $0.7 \mathrm{~cm}$ per year. When an adrenal incidentaloma is found, careful follow-up is needed for several years because the lesion may actually be a pheochromocytoma.

The authors state that they have no Conflict of Interest (COI).

\section{References}

1. Young WF Jr. Clinical practice. The incidentally discovered adrenal mass. N Engl J Med 356: 601-610, 2007.

2. Doijiri R, Sakamoto K, Hashimoto T, et al. Study on upper limit of normal range of spot urine total metanephrine level in patients with hypertension or adrenal tumor. Med J Iwate Pref Hosp 49: 11-14, 2009 (in Japanese).

General Internal Medicine, Iwate Prefectural Central Hospital, Japan

Received for publication September 17, 2010; Accepted for publication November 29, 2010

Correspondence to Dr. Takashi Sugawara, sugataka@chuo-hp.jp

(C) 2011 The Japanese Society of Internal Medicine Journal Website: http://www.naika.or.jp/imindex.html 